\title{
Development of a Measuring Sensory System Based on LabVIEW for Determining Elastic Proprieties of Solid Materials
}

\author{
Zakaryae Ezzouine ${ }^{1}$, Abdelrhani Nakheli ${ }^{2}$ \\ ${ }^{1}$ Lab.Spectometry of Materials \& Archeomaterials (LASMAR), Faculty of Sciences, Moulay Ismail University, Morocco \\ ${ }^{2}$ Departement of Electrical Engineering, ESTM, Moulay Ismail University, Morocco
}

\begin{tabular}{l} 
Article Info \\
\hline Article history: \\
Received Dec 1, 2015 \\
Revised Jul 5, 2016 \\
Accepted Jul 18, 2016 \\
\hline
\end{tabular}

Keyword:

Elastic proprieties Electromagnetic sensor Experimental setup LabVIEW software Measurement

\begin{abstract}
This article develops also a measure and prototype to allow the acquisition of real time data for display, analysis, control and storage with a proposed test program for determining the model parameters. The aim is to be able to measure, and apply moment to a specimen, and collect data from the resulting deformation in the material. At the same time, the reliability of this test system has been proved by precision analysis and data processing for a simple test validation (metal wire). The force-deformation curves of solids materials in this tensile test are measured accurately in real time, to obtain the values of solid materials mechanical property parameters, The minimal change in length of the test Specimen that can be resolved by this system is $1 \mu \mathrm{m}$, which yields the sensitivity comprised between $10-4 \mu \mathrm{m}$ and $10-5 \mu \mathrm{m}$. Based on the experience that compressive tensile test have the smallest statistical scatter and that they are simplest to carry out. The measuring device can improve the measuring efficiency and accuracy distinctly while has advantages of simple configuration, low cost and high stability.
\end{abstract}

Copyright () 2016 Institute of Advanced Engineering and Science. All rights reserved.

\section{Corresponding Author:}

Zakaryae Ezzouine,

Laboratory Spectometry of Materials and Archeomaterials (LASMAR),

Faculty of Sciences, Moulay Ismail University,

BP 4010, Zitoune, Meknes, Morocco.

Email: ezzouine.zakaryae@gmail.com

\section{INTRODUCTION}

Mechanical testing plays an important role in evaluating fundamental properties of engineering materials as well as in developing new materials and in controlling the quality of materials for use in design and construction [1]-[2], and can help in the selection of the most appropriate material for many engineering projects and in developing techniques to modify a material's properties so that we can customize the material to a specific purpose [3]. If a material is to be used as part of an engineering structure that will be subjected to a load, it is important to know that the material is strong enough and rigid enough to withstand the loads that it will experience in service. As a result engineers have developed a number of experimental techniques for mechanical testing of engineering materials subjected to tensile loading [4]-[8].

The most common type of test used to measure the mechanical properties of a material is the tensile Test. This last one is performed for several reasons. The results of tensile tests are used in selecting materials for engineering applications. Tensile properties frequently are included in material specifications to ensure quality. Tensile properties often are measured during development of new materials and processes, so that different materials and processes can be compared. Finally, tensile properties often are used to predict the behavior of a material under the load. The determination of the Elastic properties also may be of interest, but special techniques must be used to measure these properties during tensile testing [9]-[11]. 
Miniature tensile testing techniques to obtain the mechanical properties of materials have been an interest of many researchers [12]-[16]. Partheepan et al proposed a simple miniature disc-type tensile specimen and fixtures to hold specimens with the help of a rigid pin to predict the mechanical properties of materials [12]. They verified the feasibility of the sample geometry using finite element method (FEM) analysis.

This paper describes the implementation of LabVIEW, in a tensile test experiment in the strength of material laboratory to allow the acquisition of real time data for display, analysis, control and storage [17][18]. The aim is to be able to measure and apply load to a specimen, and collect data from the resulting deformation in the material. The Stress and strain is calculated using the engineering equation [19]-[20], and using the values of stress and strain the true stress strain curve was plotted.

The work described in this paper provides an easy, fast and low cost test measurement of the proprieties mechanical of the materials. The paper is organized as follows: Section 1 descirbes the performance of the electromagnetic sensor and the materials. Section 2 gives the procedure method detailed for the tensile test and the calculation of the properties mechanic of metal by the experimental setup. Section 3 gives the results and discussion while conclusions and future works are drawn in section 4 .

\section{MATERIALS AND METHODS}

\subsection{Displacement Electromagnetic Sensor}

The proposed sensor is an electromagnetic sensor of displacements. Of such sensor consists essentialy of two coils and Calibrated Spring, which can be used to obtain deformation measurements of the specimen testing (See Figure1).

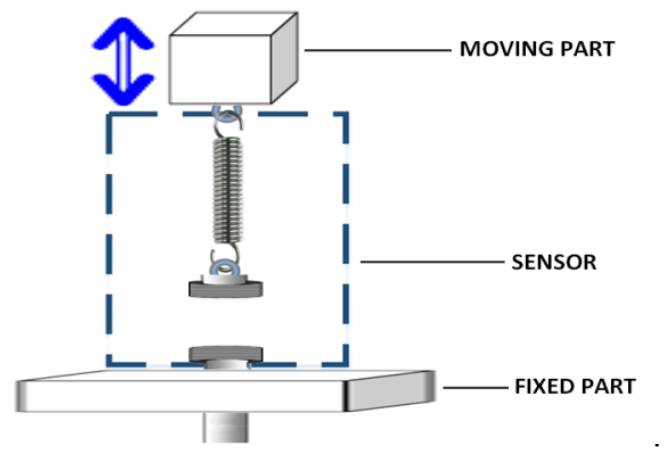

Figure 1. Displacement electromagnetic sensor.

The coil sensor operate on the basic principle that phenomenon of influence with magnetic induction between two flat coils of the same diameter $(2 \mathrm{~cm})$ and having the same number of coil turns (30) made by a copper conductor wire of a section $0,06 \mathrm{~mm}$, placed in parallel. The entire system formed (fixed flat coil, guide roller, spring and moving flat coil) is aligned on the same vertical axis.

The fixed coil is supplied by a low frequency generator of a frequency $\mathrm{F}_{0}=16 \mathrm{kHz}$ whose phase conditions and amplification are satisfied; therefore, it is traversed by a sinusoidal current which creates a sinusoidal magnetic induction variable along its axis. This induction produces a variable flux $\Phi$ and a variable induced electromotive force (EMF) on the electrons of the other coil (moving coil) equal to:

$$
e=-\frac{d \Phi}{d t}
$$

This EMF is proportional to the applied load, when the applied mass (load) increases, the inter coil distance decreases, is indeed the Out voltage of sensor and the EMF increases. A mechanical inverter (calibrated spring) is used to convert the applied load to the displacement. More details about the electromagnetic sensor system can be found elsewhere [17]-[18],[21]-[23]. 


\subsection{The Conditioning Circuit}

As shown in Figures 2, 3 and 4 the conditioning circuit of out displacement sensor signal path has three stages [17],[18],[22],[23]. For that reason, stabilizing and increasing the out sensor voltage requires several processes.

The first step is finding the gain of the amplifier and multiplying this gain with the sensor voltage, finding the gain of an amplifier stage can be cumbersome.

Figure 2 shows a non-Inverting gain amplifier using an op amp. It presents high impedance to the sensor (at VSENSOR) and produces a positive gain from VSENSOR to V1.

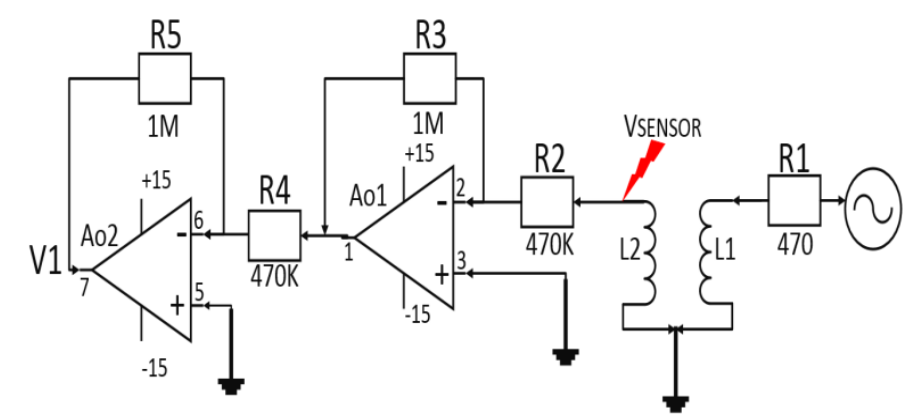

Figure 2. Non-inverting Gain Amplifier for High-Impedance Sensors with Voltage Output; L1: Transmitter coil; L2: Receiver coil

(Figure 2) used in the application can be seen in equations 2 and 3.

$$
\begin{aligned}
& V_{\text {opAmp 1 }}=\frac{R 2}{R 1} V_{\text {SENSOR }}, \\
& V_{\text {opAmp 2 }}=V 1=\frac{R 4}{R 3} * \frac{R 2}{R 1} V_{\text {sensor }},
\end{aligned}
$$

The circuit shown in Figure 3 is composed of a full-wave rectifier circuit, a low-pass RC filter followed by an operational amplifier, the closed loop gain is:

$$
A C L=\frac{R 8}{R 9}+1
$$

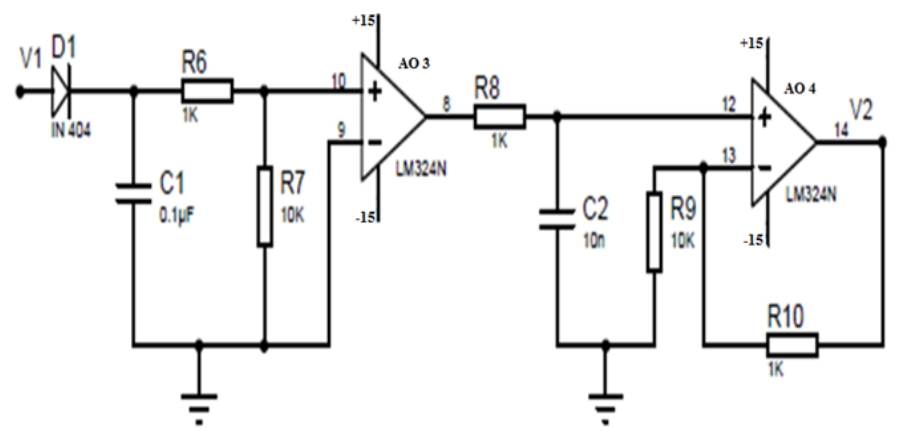

Figure 3. Full-wave rectifier circuit and Low Pass Butterworth Filter

The conditioning circuit also includes an adjustable control potentiometer resistor used to adjust the sensitivity of sensor. 


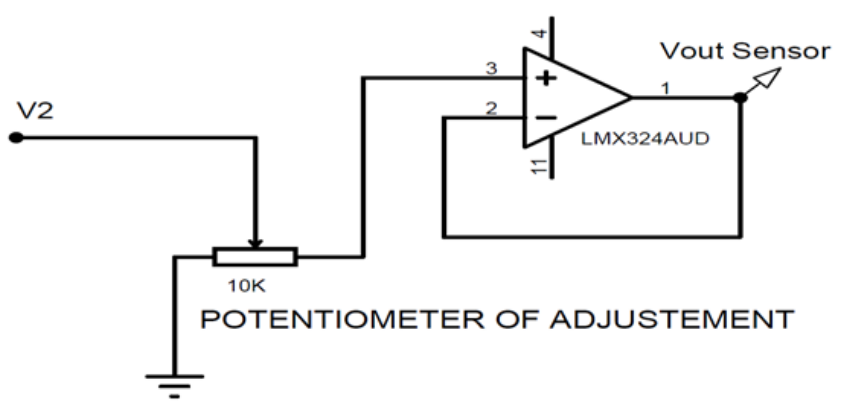

Figure 4. Potentiometer for adjustment

The Amplifiers used in the Conditioning circuit are LM324 which are power supplied from a $\pm 15 \mathrm{~V}$ symmetrical stabilized source [21].

\subsection{Specimen Testing}

In Figure 5 we show a test specimen is designed of a standard shape and dimensions, based on a conventional standard tensile specimen. A specimen is prepared according to experimental set up standard test method for tensile properties elastics of metals; it's subjected to an axial load.

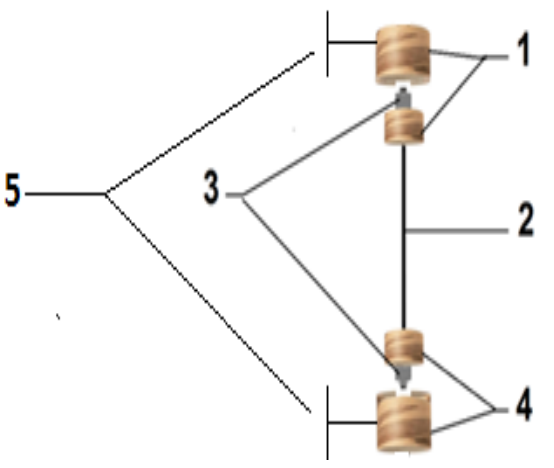

Figure 5. Design of the Tensile Specimen: 1, liner support cylinder; 2, Wire sample; 3, support post nut; 4, liner support cylinder; 5, Clamps

The test piece is made of a metal wire, which is gripped at its ends by two cylinders to prevent the wire from being removed, and it's clamped in the two cylinders by clamps for fixing the wire and to ensure the application of the traction force over the entire section of the wire. The specimen is pulled to elongate at a determined rate to its breakpoint.

\subsection{Experimental Setup}

The experimental set up is an accurate Tensile Test System measures the physical properties of very small objects, such as metal materials. The system measures samples between $5 \mathrm{~cm}$ and $60 \mathrm{~cm}$ with loads up to 196 Newton. The measuring system shows in Figure 6 consists of a computer for test control and display, a sample test specimen with a rigid support, and a hook to suspend the applied load. 


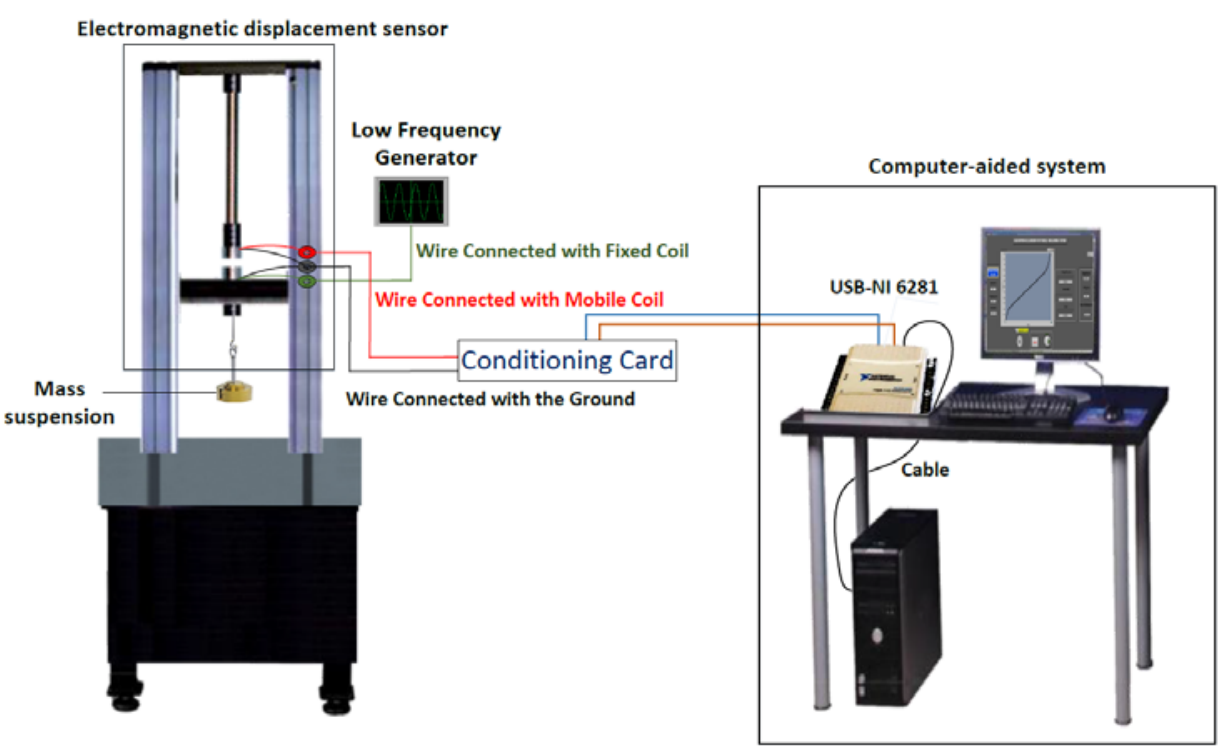

Figure 6. Experimental setup

In addition, the system contain Electromagnetic force-displacement sensor to measure deformation of the sample. A data acquisition card allows the visualization and the monitoring of the applied load as well as the elongation of sample. PC-based on LabVIEW software in the system collects and analyzes a variety of engineering properties such as Modulus of Elasticity, yield strength, ultimate strength, failure strength, and elongation at failure.

\subsection{Procedure of Tensile Test}

Tensile test is carried out by gripping the ends of a suitably prepared standardized test piece in a tensile testing device, and then applying a continually increasing uni-axial load until such time as failure occurs. The test piece must be standardized so that results can be replicated and compared. Before the test, the specimen length (Lo), and the cross-sectional area (Ao) are measured to enable calculations of strain.

A test setup is shown in Figure 5 a typical wire has a placed in the testing device and a force $\mathrm{F}$, called the load, is applied, Therefore the inter coil distance decreases and the out voltage of sensor increase .A Voltage-Inter coil distance curve used to measure the amount that the specimen stretches between the distance inter coil when the force is applied. Thus, what is measured is the change in length of the specimen $(\Delta \mathrm{L})$ over a particular original length (L0). Information concerning the strength, Young's modulus, and stress of material can be obtained from such a tensile test.

In a tensile test, the engineering stress, or nominal stress, $\sigma$ is defined as:

$$
\sigma=\frac{F}{A 0}
$$

Where $\mathrm{F}$ is the tensile force and Ao is the cross-sectional area. The engineering strain, or nominal strain, $\varepsilon$ is defined as:

$$
\varepsilon=\frac{\Delta L}{L 0}
$$

Where Lo is the initial gage length and $\Delta \mathrm{L}$ is the change in length (L- Lo).section of the wire. The elongation is measured by the Following equation:

$$
\Delta L=d_{2}-d_{1}
$$

Where $\mathrm{d} 1$ is the initial inter Coil distance, and $\mathrm{d} 2$ is the inter coil distance at: Load $\mathrm{P}=12.2625 \mathrm{~N}$. 


\subsection{Data Acquisition}

The data experimental is interfaced to the computer connected through the National Instruments multifunctional NI USB-6281 data acquisition module card which can support 16 analog inputs and 2 analog outputs channels with a voltage ranging between \pm 12 Volts. The sampling rate of the acquisition card module is $625 \mathrm{Ks} / \mathrm{S}$ with 18 bit resolution. The graphical program written in LabVIEW is then linked to the set up through the acquisition module.

The physical and electrical connection between Experimental system, conditioning card and DAQ is shown in Figure 5. Analogue inputs channels are configured for differential measurements.

A graphical software package such as the LabVIEW® for Windows, from National Instruments, Austin, Texas was used to provide the user interface. LabVIEW® provides tools for instrument control, data acquisition, data analysis. With the graphical programming language, the user wires block diagrams in a logical sequence to create what are called virtual instruments (VIs). Each VI can be programmed to run alone or be embedded into a single hierarchical VI. This modular approach to programming is extremely versatile and allows greater complexity and sophistication, without creating a large and indecipherable assemblage of wires and icons. For each specific control, acquisition, and analysis function provided by the controller card, a library of VIs can be assembled. These VIs can then be used together to create specific testing procedures.

\section{RESULTS AND VALIDATION}

\subsection{System Calibration}

In order to measure elastic property of metal, the sensor was preliminary calibrated, the linear relation between output Voltages and applied forces was estimated.

The calibration of the load was conducted by collecting data of different known applied loads (weights) and measuring its corresponding output voltage. Calibration measurements were conducted by steps over a range of 0 to $196 \mathrm{~N}$ with an elapsed-time of $1 \mathrm{~min}$ between each calibrated load in order to avoid hysteretic effects, the voltage returns to Zero value after removing the load. A series of calibrated loads were applied in increasing order. The output voltage of the load was captured through a high-resolution program developed in LabVIEW.

Figure 7 shows the obtained polynomial behavior between the applied loads (m) and the output voltage (V) as obtained from the load. Where the applied loads (m) is given in grams and the output voltage $\mathrm{V}$ in multivolts.

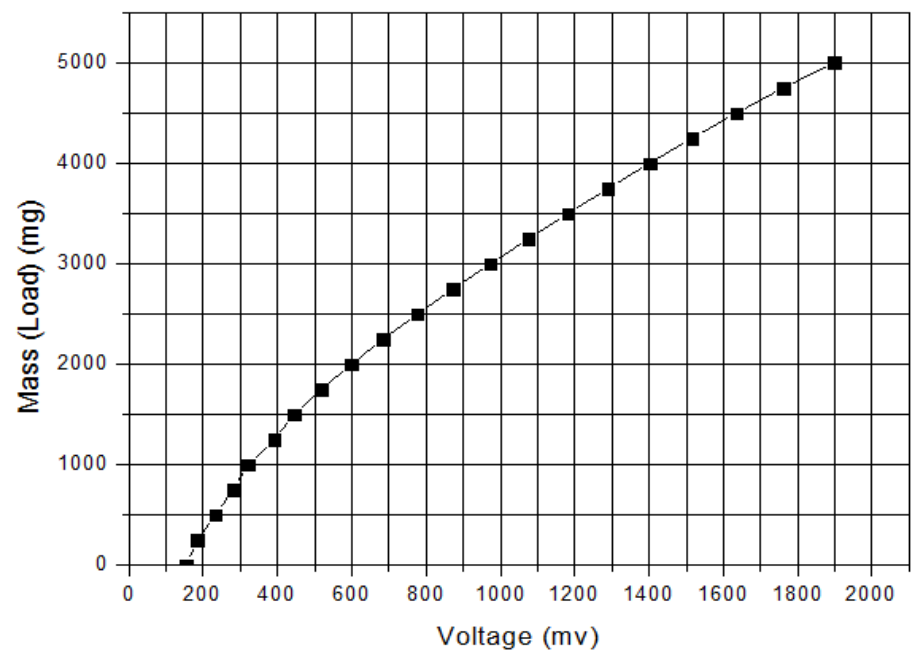

Figure 7. Calibration curve $\mathrm{m}=\mathrm{f}(\mathrm{V})$

The electromagnetic sensor is comprised of a converter (a calibrated spring) that allows the Conversion of the masses in displacements (see Figure 8). The curve of Determination of the displacement $\mathrm{d}=\mathrm{f}(\mathrm{v})$ obtained by conversion the masses in displacement while using the characteristic for spring $(\mathrm{K}=9.81 \mathrm{~N} / \mathrm{m})$. 


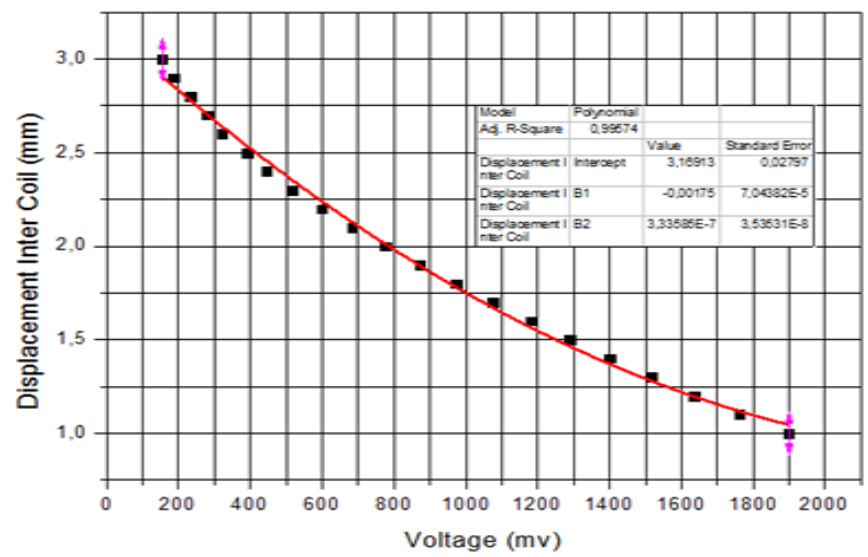

Figure 8. Calibration curve showing the relation between inter-coil distance and out voltage of Sensor $\mathrm{d}=\mathrm{f}(\mathrm{V})$

The fit polynomial to the curve shown in Figure 8 is of order 2, characterized by a standard deviation consistent with the experimental accuracy of the sensor $(\Delta \mathrm{V}= \pm 0.01 \mathrm{mV})$, appears suitable:

$$
d(m m)_{i}=\sum_{j=0}^{2} B_{j}^{*} v_{i}^{j}
$$

The coefficients of the polynomial fit are: $\mathrm{B}_{0}=3.16913 ; \mathrm{B}_{1}=-0.00175 ; \mathrm{B} 2=3.33585 . \mathrm{E}^{-7}$. The equation describing this relationship between the Inter coil distance and the out voltage of sensor can be expressed by:

$$
d(m m)=3.335 * 10^{-7} \times V^{2}-17.5 * 10^{-4} \times V+3.169
$$

After the calibration of the Sensory system Device we replace the spring calibrated by the fixing system and the test sample.

\subsection{Validation of the Experimental setup by Measurement the Elastic properties of copper Wire}

In order to understand the effects of the tensile testing on mechanical properties, a commercial copper wire of $16 \mathrm{~mm}$ length, $0.025 \mathrm{~mm}$ in thickness and $4.90625^{*} \mathrm{E}^{-08} \mathrm{~mm}^{2}$ in Area was provided to acquire the optimal condition with respect to Experimental setup. Also this sample test used to valid the measurement system. The results of experimental test are summarized in Table 1.

Table 1. Summary of tensile test results from copper wire

\begin{tabular}{ccccc}
\hline $\mathrm{M}(\mathrm{Kg})$ & $\mathrm{P}(\mathrm{N})$ & $\mathrm{V}(\mathrm{mv})$ & $\mathrm{d}(\mathrm{mm})$ & $\Delta \mathrm{L}(\mathrm{mm})$ \\
\hline 0 & 0 & 300 & 2.6741 & 0 \\
1.25 & 12.2625 & 312.1 & 2.6554 & 0.0187 \\
2.5 & 24.525 & 328.4 & 2.6304 & 0.0250 \\
3.75 & 36.7875 & 348.2 & 2.6002 & 0.0301 \\
5 & 49.05 & 372 & 2.5642 & 0.0359 \\
6.25 & 61.3125 & 399 & 2.5239 & 0.0403 \\
7.5 & 73.575 & 429.7 & 2.4787 & 0.0452 \\
8.75 & 85.8375 & 464.5 & 2.4282 & 0.0505 \\
10 & 98.1 & 503.1 & 2.3731 & 0.0550 \\
11.25 & 110.3625 & 546 & 2.3130 & 0.0600 \\
12.5 & 122.625 & 593.5 & 2.2480 & 0.0650 \\
13.75 & 134.8875 & 646 & 2.1778 & 0.0701 \\
15 & 147.15 & 703.8 & 2.1027 & 0.0751 \\
16.25 & 159.4125 & 768.1 & 2.0217 & 0.0809 \\
17.5 & 171.675 & 838.2 & 1.9366 & 0.0851 \\
18.75 & 183.9375 & 920 & 1.8414 & 0.0951 \\
20 & 196.2 & 1028.7 & 1.7219 & 0.1195 \\
\hline
\end{tabular}

With: m, Mass; P, Load; V, Tension; d, Displacement and $\Delta$ L, Elongation. 
A National Instruments USB-6281 data acquisition card is used to acquire the analogue signals from the out Voltage of sensor as function of the applied loads as well as the Elongation. The application software of the system is written in LabVIEW 10, a graphical programming language provided by National Instruments. Figure 9 shows the frontal panel of the implemented program and the different parameters used to obtain the stress-strain curve.

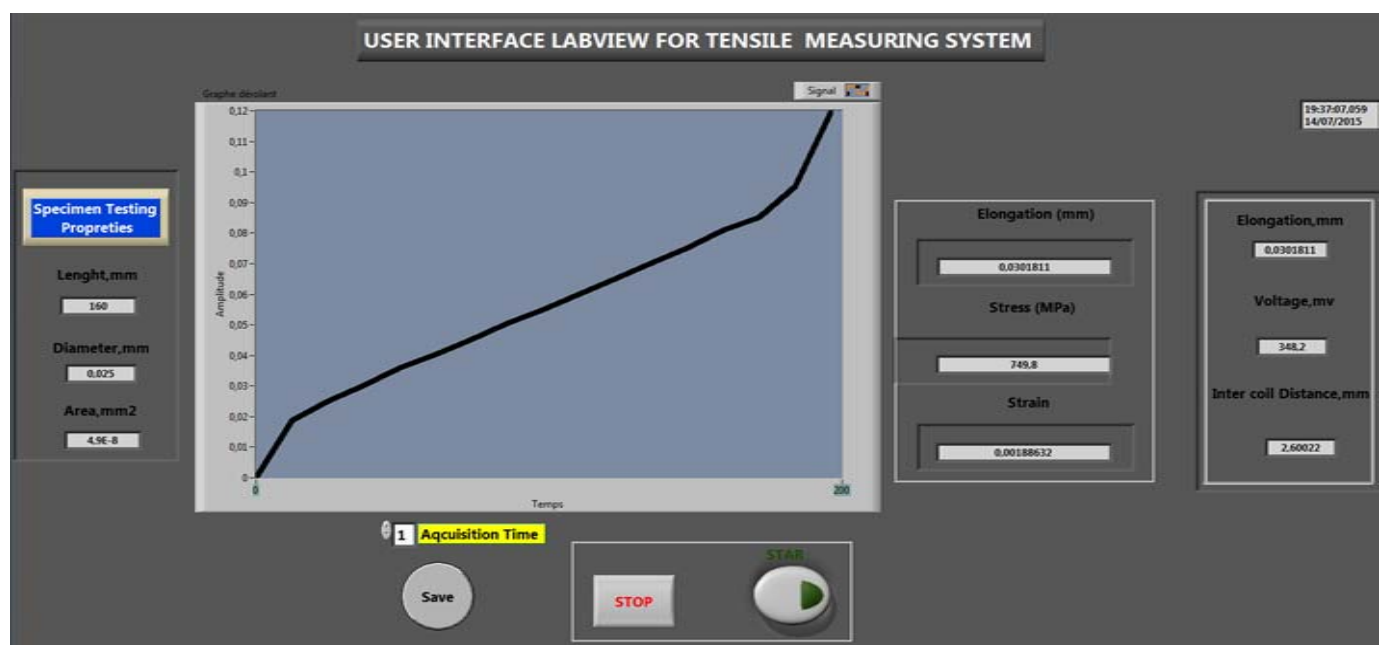

Figure 9. The user interface written in LabVIEW. The interface includes a real-time plot of the applied load against displacement. Also included are parameters for the sample setup

The graphical user interface (GUI) provides the user with complete control and monitoring over all aspects of the tensile testing system. Geometrical details such as the length, area and thickness of the test specimen are supplied to the software.

The force-displacement and stress-strain curves are plotted in real time during testing. Using this program, parameters as data acquisition time, displacement, and applied force can be captured and saved in real time for subsequent analysis. All data gathered throughout the experiments can be exported to a text file for further processing using a spreadsheet tool. Figure 10 shows a plot of the applied Load as function of Elongation (load-displacement curve) obtained from the experiment.

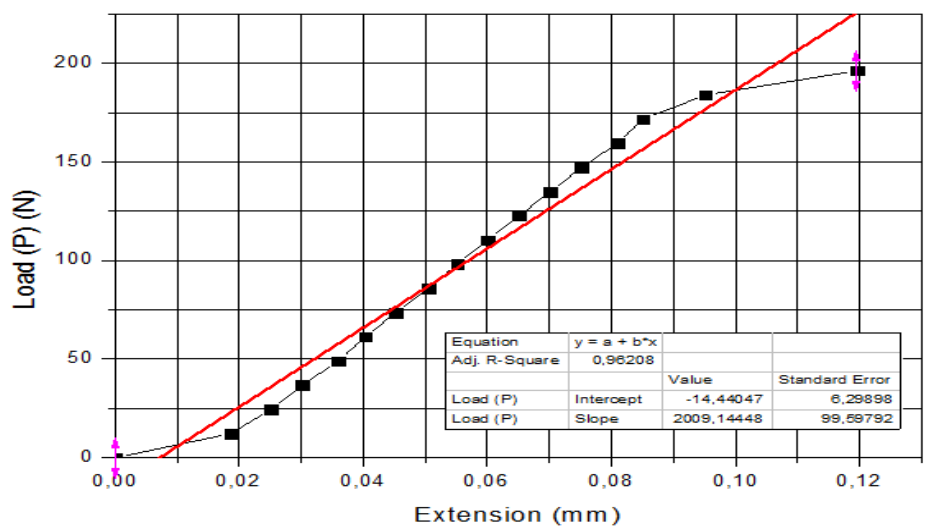

Figure 10. Force-Elongation curve for Copper Wire

The engineering stress vs. engineering strain curve from the tensile test is shown in Figure 11. The curve clearly exhibits a linear-elastic regime (dotted line in Figure 11). The consistency of the measured stress-strain values is evident from the good reproducibility of the linear-elastic region. 


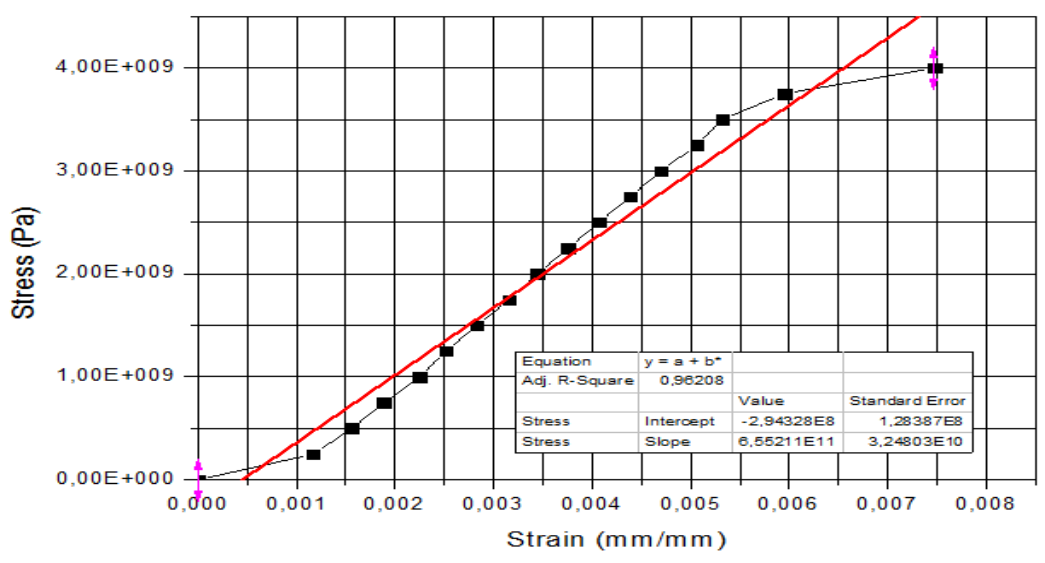

Figure 11. The engineering stress-strain curve of the copper wire alloy at various applied Load

Once the tensile stress-strain curve is plotted, the Young's modulus, E, of the copper wire is determined from the slope of the initial linear region. In the figure above a tangent draw on the curve is show at a stress of $199.94 * 10^{6} \mathrm{~Pa}$. The slope of this line (i.e., $\Delta \sigma / \Delta \varepsilon$ ), the tangent modulus, is computed as follows:

$$
\frac{\Delta \sigma}{\Delta \varepsilon}=\frac{199.94 * 10^{6}-174.95 * 10^{6}}{0.0034-0.0031}=83.3 \mathrm{GPa}
$$

The percentage error of linear Young Modulus from this experiment compared to that of literature is $35.9 \%$ of Copper wire [24]-[25]. It has a pretty good precision. From the results, they indicate that this technique is simple for measuring the Elastic proprieties of metals using readily available materials.

\section{CONCLUSION}

This article described a method to evaluate material properties using a simple tensile testing system with a miniature specimen through a simple experimental setup. The proposed method is based on Electromagnetic Displacement Sensor with accurate $10^{-3} \mu \mathrm{m} / \mathrm{mv}$. A measurement tensile testing system was designed and developed. The newly designed specimen is small in size and easy to prepare. Finally, the developed testing system can be used as a Technical design of didactical tools instructional to assist students in their efforts to understand the basic mechanical properties of materials.

In this experiment, Program has been created using LabVIEW used to investigate the mechanical properties of metals materials subjected to the tensile load.The use of virtual instruments created with LabVIEW allows the user to quickly investigate and gather data. The experimental system conforms to the specifications of standard test method. The Young's modulus and tensile strength of copper wire, as determined from the tensile tests agrees with the previously reported values.

Successful achievement of this work will allow us, as future work, we think to make measurements in other solid materials and determining their property mechanical by this simple experimental measurement system, and also to increases the performance and the sensibility of the system, then we need to replace the present calibrated spring of the electromagnetic sensor by another more susceptible in the future, which greatly lengthens the precision of the measurement system.

\section{REFERENCES}

[1] G. E. Dieter, "Mechanical metallurgy," SI metric edition, Boston, McGraw-Hill, 1988.

[2] N. E. Dowling, "Mechanical Behavior of Materials," second, ed., Prentice-Hall, 1999.

[3] M. Carr, "Tensile testing: a simple introduction," Phys. Educ., vol. 41, pp. 57-62, 2006.

[4] ASTM, "E 646 Standard Test Method for Tensile Strain-Hardening Exponents (n-Values) of Metallic Sheet Materials," Annual Book or ASTM Standards, American, Society for Testing and Materials, vol. 3.

[5] ISO/TR 29381, "Metallic materials - Measurement of mechanical properties by an instrumented indentation test Indentation tensile properties," TC 164 Mechanical testing of metals/SC3, pp. 29, 2008.

[6] ASTM, "Standard Test Methods for Tension Testing of Metallic Materials," D.o. Defense., 2013.

[7] “Japanese Industrial Standards (JIS)," J.S.A., 2005. 
[8] M. S. Loveday, et al., "Tensile testing of metallic materials: A review," Technical report, National Physical Laboratory, April 2004. Project funded by the European Community under the Competitive and Sustainable Growth Program (1998-2002), Project Number GRD1-2000-25021, contract Number G6RD-CT-2000-00412. Available from: www.npl.co.uk/advanced-materials/measurement-techniques/mechanical/tensile-testing-standardsand-tenstand.

[9] W. F. Hosford, "Overview of Tensile Testing, Tensile Testing," P. Han, Ed., ASM International, pp. 1-24, 1992.

[10] P. M. Mumford, "Test Methodology and Data Analysis," ASM International, pp. 49-60, 1992.

[11] R. Gedney, "Guide To Testing Metals Under Tension," Advanced Materials \& Processes, pp. 29-31, 2002.

[12] G. Partheepan, et al., "Design and usage of a simple miniature specimen test setup for the evaluation of mechanical properties," Inter. J. Microstructure and Materials Properties, vol. 1, pp. 38-50, 2005.

[13] Y. C. Chao and D. S. Liu, "Gold Wire and Solder Joint Microforce Testing Using Microforce Tester," Experimental Techniques, vol/issue: 27(5), pp. 37-40, 2003.

[14] D. A. LaVan, "Microtensile properties of weld metal," Experimental Mechanics, vol/issue: 23(3), pp. 31-34, 1999.

[15] Z. Ma, et al., "A novel tensile device for in situ scanning electron microscope mechanical testing," Experimental Techniques, vol. 39, pp. 3-11, 2015.

[16] P. H. Hou and T. Y. Chen, "An automatic tensile test measurement system for miniature specimens," Experimental Mechanics, vol/issue: 29(4), pp. 32-36, 2005.

[17] R. David, "Stress-Strain Curves," Department of Materials Science and Engineering, Massachusetts Institute of Technology, Cambridge, MA 02139, pp. 1-14, 2001.

[18] R. Cabello, et al., "Analysis of the range of acceleration for an accelerometer with extended beams," International Journal of Electrical and Computer Engineering (IJECE), vol/issue: 6(4), 2016.

[19] Z. Ezzouine, et al., "Conception And Realisation of a Sensor Electromagnetic Force-Displacement", International Journal of Research in Engineering and Technology, vol/issue: 3(10), pp. 268-271, 2014.

[20] A. Benabdellah, et al., "New Electromagnetic Dynamometer: Measuring the Surface Tension of Liquids," International Journal of Research in Engineering and Technology, vol/issue: 3(3), pp. 257- 263, 2014.

[21] Z. Ezzouine and A. Nakheli, "A Simple Method for Determining Thermal Expansion Coefficient of Solid Materials with a Computer-aided Electromagnetic Dilatometer Measuring System," Sensors \& Transducers, vol/issue: 190(7), pp. 86-91, 2015.

[22] Z. Ezzouine and A. Nakheli, "Liquid Level Detection System With A Labview Based Pc Using An Electromagnetic Displacement Sensor," Journal of Theoretical and Applied Information Technology (JATIT), vol/issue: 79(2), pp. 338-345, 2015.

[23] A. Benabdellah, et al., "New Electromagnetic Force-Displacement Sensor," International Journal of Electrical and Computer Engineering (IJECE), vol/issue: 6(2), pp. 560-566, 2016.

[24] http://www.markedbyteachers.com/as-and-a-level/science/copper-young-s-modulus.html

[25] http://homepages.uc.edu/ bortnelj/labs/Physics 1 experiments/Youngs Modulus/Young's Modulus htm.htm

\section{BIOGRAPHIES OF AUTHORS}

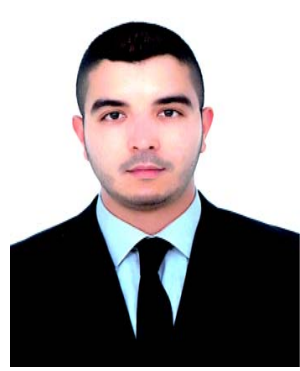

Z. Ezzouine was born on February 02, 1989 in Meknes, Morocco. He received Master degree in Microelectronics from Ibn Tofail University, Kenitra, in July 2012. He is currently pursuing PhD degree in sensor and instrumentation at LASMAR laboratory, Faculty of Science, University Moulay Ismail, Meknes, Morocco. His main area of research includes Design and implementation of an inductive displacement sensor to measure various physical parameters

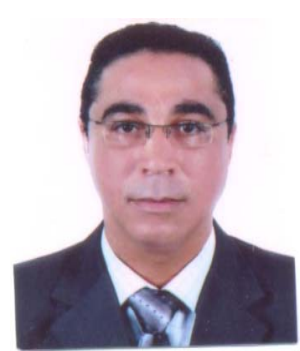

A. Nakheli was born on January 23, 1964 in Fes, Morocco. He received his PhD degree in Materials Science, 1992 at INSA, Lyon, France. He received his Diploma of State of Doctor in Physics from Moulay Ismail University Meknes, Morocco. Currently, he is a professor at Electrical Engineering Department, High School of Technology (ESTM), Moulay Ismail University of Meknes, Morocco. He is working in sensors conception and electromagnetic applications. 